\title{
PRECIOS DE BIENES IMPORTADOS EN BUENOS AIRES, 1824-1850
}

\author{
Prices of goods imported in Buenos Aires, 1824-1850
}

\section{Roberto Schmit*}

\section{Resumen}

Este trabajo analiza la evolución de los precios de bienes importados en Buenos Aires durante la primera mitad del siglo XIX. El objetivo del artículo es realizar un aporte sobre la evolución de un índice ponderado de precios de bienes importados y de la evolución diferencial de los precios relativos de aquellos productos.

$$
<\text { Precios }><\text { Precios relativos }><\text { Importación }><\text { Siglo XIX }>
$$

\begin{abstract}
This paper analyzes the evolution of the prices of imported goods in Buenos Aires during the first half of the nineteenth century. The aim of this article is to make a contribution on the development of a weighted price index of imported goods and the differential evolution of the relative prices of those products.

$<$ Prices $><$ Relative prices $><$ Import $><$ Nineteenth century $>$
\end{abstract}

Recibido: 20/05/2016 // Aceptado: 31/08/2016

El estudio de los precios constituye una herramienta significativa que permite comprender mejor un amplio conjunto de cuestiones vinculadas al desempeño de los procesos económicos y sociales. Entre las principales cuestiones de la historia de precios se destaca el análisis de la evolución general de los precios y también del movimiento de los precios relativos de los diversos rubros del mercado, los cuales posibilitan analizar en la dinámica de los mercados los potenciales márgenes de consumo y de costos de los bienes para determinados sectores de la economía. No obstante la relevancia de lo señalado, a pesar de algunos notables esfuerzos, la historiografía argentina ha producido pocos estudios sistemáticos sobre la evolución de los precios en la era decimonónica. ${ }^{1}$

1 Entre los estudios sobre el tema, podemos distinguir un conjunto de valiosos trabajos: sobre algunos bienes en particular, los de Broide (1951), Gorosteguí de Torres (1962), Bilbao (1985), Garavaglia (1995 y 2004) y el trabajo sobre un conjunto más amplio de precios de bienes y salarios, de Barba (1999); los estudios de varios productos, de Newland (1998) y de Cuesta (2009). Asimismo, están los muy significativos estudios sobre las coyunturas de bloqueos a Buenos Aires, de Halperin Donghi (1978)

\footnotetext{
* Doctor en Historia. UBA-UNGS-CONICET.rschmit@ungs.edu.ar
} 
En este trabajo puntual se aspira a realizar un aporte inicial sobre aquellas dos cuestiones significativas para la historia de los precios en Buenos Aires durante la primera mitad del siglo XIX. En primer lugar, se propone estimar un indicador ponderado de evolución general del nivel de los precios de los bienes importados en Buenos Aires entre 1824 y 1850 . Hasta el presente, los estudios han examinado solamente la evolución de algunos precios o de un grupo reducido de bienes de importación, pero no se ha estimado un índice ponderado de varios productos dando, por tanto, cuenta del potencial peso diferencial de los diversos bienes sobre la demanda de los mercados. En segundo lugar, nos proponemos analizar la evolución de los precios relativos de los bienes de ultramar; cuestión que tampoco en los trabajos ha sido explorado en detalle de cómo habrían evolucionado coyunturalmente de modo diferencial en la plaza porteña.

\section{Breve contexto del mercado en Buenos Aires}

Durante la primera mitad del siglo XIX, en Buenos Aires, la demanda de varios bienes de consumo básico, la exportación de la producción rural y los ingresos de las finanzas de la provincia resultaron dependientes de la marcha de sus conexiones con el comercio atlántico ultramarino. Todo aquello se debió a que el consumo de la población rioplatense demandaba regularmente para su sustento cotidiano una significativa cantidad de bienes importados, a que la principal economía local estaba ligaba sustancialmente al sector exportador pecuario y a que los ingresos fiscales se nutrían básicamente de los aranceles de las importaciones de ultramar, junto con un aporte menor proveniente de los productos exportados y de otras tasas impositivas.

En las últimas décadas, numerosos estudios han ilustrado con mucha claridad las principales características y ciclos que se sucedieron en la economía rural bonaerense luego de la Revolución, con un avance sostenido sobre la campaña de su frontera productiva donde se expandía una renovada economía ganadera, con la ciudad y una multitud de pequeños núcleos urbanos conectadas a una creciente red de transportes que las vinculaba. La base de aquella frontera del poblamiento y de la ocupación de la tierra estuvo ligada a una estructura productiva con una creciente producción ganadera para la exportación, como también por una densa y extensa presencia de labradores, que en diferentes escalas y formas de explotación, se constituyeron en la campaña en la médula de la economía bonaerense. ${ }^{2}$

También los estudios históricos recientes sobre Buenos Aires han terminado de mostrar claramente que durante la primera mitad del siglo hubo un rápido crecimiento demográfico de la población de la ciudad y de la campaña, que sostendrían en el mundo urbano una tasa de crecimiento entre 1822 y 1838 , del 1,03 y entre 1838 y 1854 a una

y Amaral (1988 y 1989). Más limitados en cantidad son aún los estudios sobre el precio del dinero, las monedas y crédito, disponemos de aportes pioneros de Álvarez (1929), Burgin (1960), Amaral (1988) e Irigoin (1996, 2000 y 2001).

2 Una profusa bibliografía ha ilustrado el proceso de expansión rural de Buenos Aires de la primera mitad del siglo XIX; entre los principales textos se encuentran el pionero estudio de Halperin (1963), y más recientemente, entre otros, los aportes generales muy bien sintetizados en los libros de GaravagliaFradkin (2004), Djenderedjian (2013) y Banzato (2013). 
tasa del 2,03. Por lo cual finalmente para el año 1854 la población bonaerense alcanzaba las 270,463 personas, con 90,176 en la ciudad y 180, 287 en la campaña (Mateo, 2013).

Asimismo, los trabajos sobre el comercio han examinado cómo el puerto de Buenos Aires continuó siendo la principal plaza mercantil rioplatense articuladora de un extenso espacio económico al cual conectaba con ultramar. De manera que la ciudad-puerto, como parte de un complejo mayor, no solo era la conexión natural con la economía de su amplio hinterland rural, sino que, además, acrecentó su rol de urbe comercial distribuidora y de control de los nexos y negocios mercantiles, financieros y de servicios para los tratos de un espacio comercial que incluía diversos mercados interregionales con las provincias del Litoral y del interior de circulación de bienes de exportación, pero sobre todo de los lucrativos negocios de la re-importación de mercancías ultramarinas. ${ }^{3}$

De modo que durante las décadas posrevolucionarias la provincia de Buenos Aires indudablemente había logrado conservarse como el principal eje productivo y mercantil local y regional que, tras la crisis minera alto-peruano, mediante la definitiva apertura comercial a ultramar y una renovada expansión ganadera exportadora, abrió paso a la hegemonía de un reformulado esquema comercial y productivo rural de una decisiva conexión, que implicaba un esquema complementario entre las demandas de lo urbano y lo rural.

De modo que, luego de 1810, el libre comercio en Buenos Aires introdujo más plenamente el comercio ultramarino con el interior del territorio. Impulso que además fue favorecido por un significativo descenso del costo del flete trasatlántico, que permitió una mayor rentabilidad a los bienes y aceleró los tratos intercontinentales. Todo lo cual renovó las opciones de los circuitos mercantiles, los niveles de producción rural y las nuevas prácticas de comercio. Pero en esa misma relación de intercambio, también se abrió paso una nueva época de mayor incertidumbre económica por los cambios bruscos en los flujos de comercio, producto de los ciclos de inestabilidad internacional y del marco político-institucional local.

Sumado a los cambios mencionados, a inicios de la década de 1820 la estructura fiscal porteña tomó un rumbo más definido con la promulgación de nuevas leyes de recaudación impositiva y de aranceles de aduana. En la nueva matriz del erario público, prácticamente no gravaron la propiedad ni los ingresos, por lo cual no hubo impuestos directos significativos. En cambio, se acentuó la tendencia iniciada con la Revolución de sustentar los ingresos centralmente en los recursos que proporcionaba el intercambio comercial. Es decir, la base fiscal de ingresos públicos estuvo en correlación casi permanente con los impuestos de origen indirectos vinculados al comercio y a los índices de intercambio de los bienes importados. ${ }^{4}$

Así, se puso en práctica un renovado perfil fiscal a través de una serie de reformas que terminaron de moldear los vínculos mercantiles y fiscales de la plaza ultramarina. De modo que desde entonces, como señalamos, quedó establecida una relación muy

3 Entre otros se puede ver: Halperin (1982), Irigoin-Schmit (2002), Schmit-Rosal, (2004) y Jumar (2013).

${ }^{4}$ Se puede ver el trabajo fundamental de Halperin Donghi (1982). Un balance reciente en Schmit (2013). 
estrecha entre la evolución de la actividad mercantil, la actividad productiva y el nivel de ingreso fiscal. Bajo esas características, en un contexto de ventajas mercantiles que tenía Buenos Aires, marcó una gran distancia a favor de la provincia, fruto del privilegio de manejar el puerto como única vía de acceso legal a ultramar, $\mathrm{y}$, por tanto, dispusieron de recursos sustancialmente superiores a todas las restantes provincias rioplatenses.

Dentro de aquel contexto general de la economía bonaerense, en este trabajo nos interesa abordar la evolución del nivel general de precios y de los cambios en los precios relativos de los bienes ultramarinos en la plaza porteña. Por lo cual nos interesa examinar cómo fueron afectados los precios, en sus tendencias generales y en las coyunturas, por la apertura librecambista, así como por los efectos negativos de los bloqueos comerciales sobre el puerto de Buenos Aires. Al respecto, ya disponemos de trabajos que muestran para períodos cortos y solo para algunos bienes cómo los bloqueos comerciales produjeron, sin duda, alta inflación y alteración de los precios, frente a lo cual nos interesa reexaminar el tema desde una mirada general más integral, así como prestando atención especial a los impactos diferenciales de los precios en las dinámicas temporales y en los diversos sectores económicos. ${ }^{5}$

\section{Tendencia general de la evolución de los precios de bienes importados en Buenos Aires}

En una mirada general sobre la evolución del nivel general de los precios de bienes importados, en un índice ponderado, en Buenos Aires, sin duda podemos observar un notable incremento de los precios, que desde mediados de la década de 1820, creció de manera ininterrumpida hasta mitad de siglo. Pero, es claro asimismo que en aquella tendencia se reflejaron diferencias al menos en dos momentos: el primero, de un crecimiento más moderado hasta mediados de la década de 1830; y un segundo, con una fuerte aceleración en el decenio siguiente, para concluir la suba en una meseta en los índices de los distintos tipos de bienes hacía mitad de siglo.

En términos generales, los índices, con base 100 en 1824, muestran para inicios del decenio de 1830 que sostenían un índice promedio de 250. Así, luego del primer bloqueo comercial al puerto de Buenos Aires, pasadas las grandes fluctuaciones de 1826 a 1827, los precios crecieron, en índice promedio, entre un máximo de 360 y un mínimo de 140. Más tarde, para mitad de la década de 1830, los precios tocaron sus guarismos más bajos con un índice promedio de 240. Pero, durante toda la década de 1840 surgieron las nuevas turbulencias por los siguientes bloqueos navales y políticas fiscales, con un máximo de 450 y un mínimo de 170 -mucho más fuertes entre 18381840 y en menor medida, entre 1845-47- por lo cual el índice a fin del período había trepado a un índice de 700 en promedio.

\footnotetext{
5 Los pioneros estudios sobre precios de Halperin Donghi (1978) y Amaral (1988 y 1989) han aportado
} interesantes evidencias y resultados sobre las coyunturas de los bloqueos comerciales a Buenos Aires. 
Tabla 1. Evolución del índice ponderado de los precios de bienes importados en Buenos Aires (en pesos papel)

\begin{tabular}{|c|c|}
\hline AÑO & IND-IMPORT \\
\hline 1824 & 100 \\
\hline 1825 & 114 \\
\hline 1826 & 233 \\
\hline 1827 & 359 \\
\hline 1828 & 131 \\
\hline 1829 & 149 \\
\hline 1830 & 327 \\
\hline 1831 & 273 \\
\hline 1832 & 348 \\
\hline 1833 & 327 \\
\hline 1834 & 297 \\
\hline 1835 & 201 \\
\hline 1836 & 412 \\
\hline 1837 & 386 \\
\hline 1838 & 700 \\
\hline 1839 & 1970 \\
\hline 1840 & 2394 \\
\hline 1841 & 786 \\
\hline 1842 & 1893 \\
\hline 1843 & 814 \\
\hline 1844 & 741 \\
\hline 1845 & 830 \\
\hline 1846 & 1694 \\
\hline 1847 & 1325 \\
\hline 1848 & 768 \\
\hline 1849 & 1648 \\
\hline 1850 & 790 \\
\hline
\end{tabular}

Gráfico 1. Precios generales índices ponderados de los bienes importados en Buenos Aires (en pesos papel)

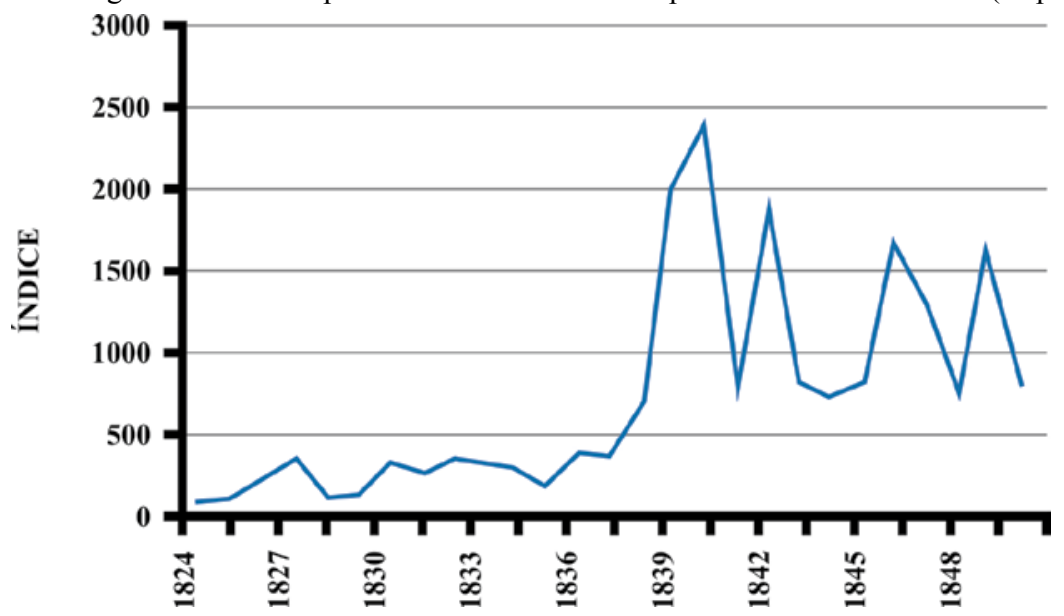

Aquellos datos de evolución nos marcan un incremento general de los precios nominales en pesos papel moneda de seis veces durante el período de 1824 a 1850 . El incremento se repartiría con al menos un $150 \%$ en la primera década y con otro, de un 
$450 \%$ para el resto del período analizado. Pero, como es muy visible en el siguiente apartado, aquel incremento global tuvo variaciones muy diferentes entre los diversos tipos de bienes importados, que tuvieron alteraciones desiguales a lo largo de los decenios examinados. De modo que se observan en los índices individuales, que los diversos bienes impactos diferentes en magnitudes y en temporalidades respecto del aumento de los precios. ${ }^{6}$

\section{Evolución relativa de los precios de bienes importados en Buenos Aires}

Para analizar la evolución de los precios de bienes de importación en Buenos Aires hemos tomado una canasta de diversos productos que entendemos representaban a grosso modo algunos de los principales bienes que se demandaban en el mercado de la ciudad-puerto. Esos bienes importados -consumidos ampliamente en el Río de la Plata-, debemos aclarar, eran productos de procedencia muy variada, como fueron las plazas sudamericanas para el caso del arroz y la azúcar blanca del Brasil y de la yerba mate de Paranaguá. En tanto, otros casos tenían su origen en regiones más distantes (América del Norte, Europa y África) del mundo ultramarino como eran el aceite, las galletas, la harina, el aguardiente, el vino Carlón o la Sal de Cabo Verde. ${ }^{7}$

Como podemos observar en el gráfico 2 , sin duda los bienes importados de ultramar en el período estudiado registraron en precios nominales en papel moneda una sostenida tendencia al alza. Pero, al mismo tiempo ellos registraron una gran diversidad y significativa volatilidad en sus registros, sobre todo fruto del impacto desigual producidos por los bloqueos comerciales y por la demanda potencial de esos bienes.

Así, por tanto, es necesario tener muy en cuenta que el alza fue diversa entre los bienes importados, que registraron en los casos más extremos que curiosamente se trata de los bienes de plazas sudamericanas muy significativas alzas y una gran volatilidad, registrando súbitos cambios desde mediados de la década de 1830, con enormes oscilaciones sobre todo desde los bloqueos de 1838-40 y 1846-48. En tanto, los bienes importados desde otras plazas ultramarinas, más lejanas también, sostuvieron una tendencia creciente pero mucho menor y con oscilaciones más estables, con menos de volatilidad, durante el período analizado.

\footnotetext{
${ }_{6}$ Respecto del peso de los bienes importados sobre la economía porteña, hay diversas opiniones respecto de su peso sobre el consumo doméstico. Gelman y Santilli calculan ese peso en un $20 \%$ sobre los consumos, en tanto Halperin y Burgin plantean que el consumo habría sido más significativo. De todos modos es necesario tener en cuenta dos pesos diferenciados sobre la evolución de su demanda. Uno el de los bienes importados sobre el consumo del amplio espacio mercantil ligado al puerto de Buenos Aires y otro el de los sectores populares de la provincia. Otra cuestión significativa sobre este tópico es que productos o canasta de consumo refleja mejor la demanda proporcional de los bienes importados. En este trabajo tomamos algunos productos de consumo extendido de la población rioplatense, pero a futuro sería necesario al menos agregar otros bienes como el de algunos textiles baratos. Para realizar una mejor ponderación sobre la canasta de consumos es necesario profundizar en los estudios del peso porcentual de diversos bienes en las importaciones de las provincias y sobre todo del consumo de los sectores populares, urbanos y rurales. Respecto de la conformación y ponderación de los índices de bienes importados (INPONIMPO), ver apéndice.

${ }^{7}$ En el apéndice se explicita cómo ha sido constituida la canasta de bienes en base a la cual se compone el índice de precios de ultramar.
} 
Gráfico 2. Precios de los bienes importados en Buenos Aires: arroz, azúcar, aceite, aguardiente, vino, sal, yerba mate (en pesos papel)

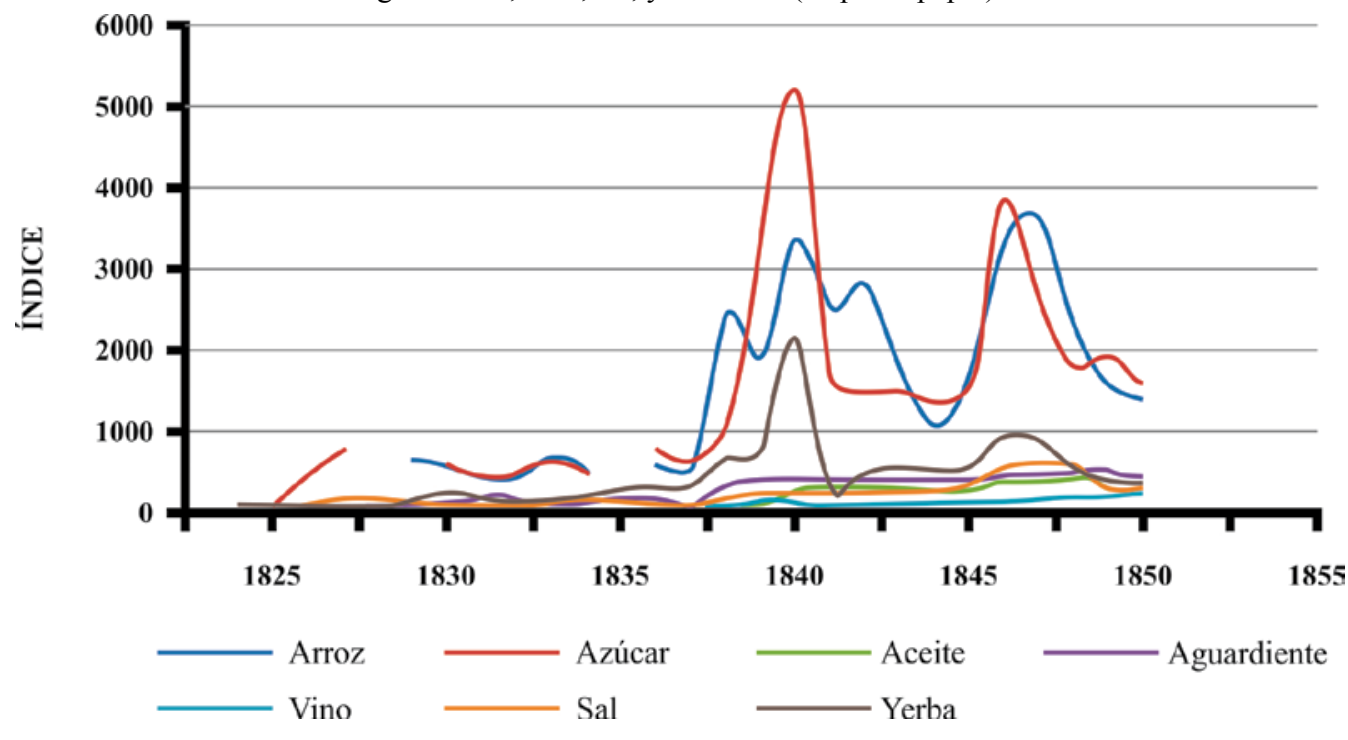

De aquella manera, sin duda, se destacaba el crecimiento acelerado de los precios nominales de los productos sudamericanos desde mediados de la década de 1830, lo cual explicaría en buena parte las motivaciones y solicitudes que, por entonces, surgieron de la sustitución en la plaza porteña de algunos de esas producciones por parte de las economías del Litoral de los Ríos.

Aquella cuestión fue notable sobre todo en los debates del contexto previo al Pacto Federal, y más precisamente en la postura de los líderes correntinos, que sostuvieron durante la década de 1830 y 1840 un intento de influenciar a la política mercantil librecambista porteña de agregar mayor protección sobre aquellos productos $\mathrm{y}$ favorecer a los productores correntinos de yerba mate y tabaco para poder abastecer a Buenos Aires y a los mercados regionales. De modo que la cuestión provocó polémicas entre las autoridades políticas de las provincias confederadas y una disputa mercantil y arancelaria en la cual los correntinos pretendieron avanzar aprovechando las dificultades coyunturales de la oferta de bienes competitivos sudamericanos buscando el apoyo de Buenos Aires. Pero, los productos litoraleños, por su escasa capacidad competitiva, por su baja calidad como sustitutos y por falta de una tarifa arancelaria proteccionista no tuvieron éxito como producciones instaladas a la par de los flujos mercantiles ultramarinos en el espacio rioplatense (Schmit, 1991).

\section{Evolución diferencial de los precios de los bienes importados en moneda fuerte}

Como ya vimos, en los primeros apartados, la evolución del nivel de precios de bienes importados en pesos papel no fue una constante de igual intensidad y el aumento 
de los mismos tampoco fue homogéneo, pero ¿cómo afectó esa diferencial de los precios en moneda fuerte a los diversos mercados de la economía rioplatense? ${ }^{8}$

En su ya clásico estudio, Burgin sostuvo que -fruto del movimiento de los precios- hubo dos procesos de transferencia de recursos en Buenos Aires. Por una parte, el efecto de la inflación que no se repartió igual en todas las clases, pues los precios subieron más rápido que los salarios, por lo cual el salario real habría decrecido. Por otra, tampoco todos los precios subieron igual: los precios externos fluctuaron al valor del oro, mientras los internos fueron por detrás, por lo cual se beneficiaron los exportadores y se perjudicaron los comerciantes, industriales y artesanos del mercado local (Burgin, 1960).

Por su parte, Amaral sostuvo que la inflación también afectó de manera diferencial a los diferentes sectores. Pero agrega que ella no solo fue un factor determinante en términos de evolución de los precios, sino también lo habría sido en relación con las cadenas de pagos a futuro de las deudas; de esa manera, el autor marca dos temporalidades de los efectos inflacionarios: el primero podría haber beneficiado a los exportadores; en tanto, el segundo habría afectado a todo el conjunto de los sectores de la producción local bonaerense (Amaral 1989).

En tanto, Irigoin ha manifestado en sus estudios que el proceso inflacionario con medios de pagos muy volátiles sustancialmente habría aumentado sobre todo los costos de las transacciones de toda la economía y habría deteriorado la evolución de las finanzas públicas de la provincia. Así, el principal efecto de la inflación habría sido la incertidumbre constante de los precios relativos, por lo cual se encareció y dificultó el crédito y la toma de riesgo fruto del contexto inflacionario de precios. De modo que para la autora, los efectos, en buen grado, habrían alcanzado a toda la economía llevando a los agentes económicos a reproducir un comportamiento económico de preferencia en su perfil de inversión, el cual se caracterizaba por sostener una mayor liquidez de capital y de realizar inversiones complementarias para disminuir los riegos, todo lo cual habría favorecido la inversión en bienes de resguardos de valor y con mercados más estables, como por entonces eran la tierra y el ganado, en detrimento de otras posibles inversiones que tenían un margen más alto de riesgo (Irigoin, 2004).

Para evaluar los efectos sobre los diversos sectores de la economía de Buenos Aires y de los mercados rioplatenses -respecto de la evolución de los precios-, nos parece razonable realizar el ejercicio metodológico de medir los precios de los diferentes tipos de bienes en precio oro (la moneda de resguardo de valor) para poder visualizar su evolución a lo largo del período.

Si tomamos en cuenta los resultados de los precios en oro de los bienes importados, que muestran los gráficos siguientes, podemos constatar que ellos, en general, parecen haber sostenido una tendencia a la baja, aunque también en las coyunturas, el panorama fue diverso dentro del escenario. Así, entre los productos de

\footnotetext{
8 En este trabajo no consideramos los efectos de la inflación y del cambio de los precios relativos sobre los actores sociales y el nivel de consumo o de vida. Estas cuestiones están siendo examinadas recientemente por interesantes estudios como son, por ejemplo, los de Gelman y Santilli (2014).
} 
origen sudamericano hubo una menor tendencia a la baja, con muchas oscilaciones e incluso con momentos de incremento, a lo largo del lapso estudiado. No así con respecto a otros bienes del mercado atlántico que más bien sostuvieron a lo largo del período una caída permanente y pronunciada de sus precios en oro. Este comportamiento, entendemos, estaba relacionado con el peso que los mismos tenían de demanda mercantil extendida en los mercados rioplatenses, así como por la dificultad de tener bienes sustitutivos, como mencionamos en el apartado anterior. En tanto, en el resto de los bienes, la demanda era de una intensidad menor y con bienes sustitutivos locales y de la propia plaza ultramarina.

En cuanto al impacto del mismo sobre los diversos sectores, estimamos que en función de los términos de intercambio, tal como ya había mostrado en su estudio Newland, no hubo tanta brecha negativa de esos términos en la tendencia general, aunque en base a nuestro índice ponderado de precios de bienes importados, esa brecha sí habría comenzado a ser desfavorable sobre todo desde la década de 1840 hasta mitad del siglo XIX. Lo cual en Buenos Aires no habría beneficiado en un margen tan significativo a los sectores exportadores, aunque sí es probable que contribuyera, como afirma Irigoin, a volcar inversiones a los sectores rurales frente a la incertidumbre de otras potenciales inversiones.

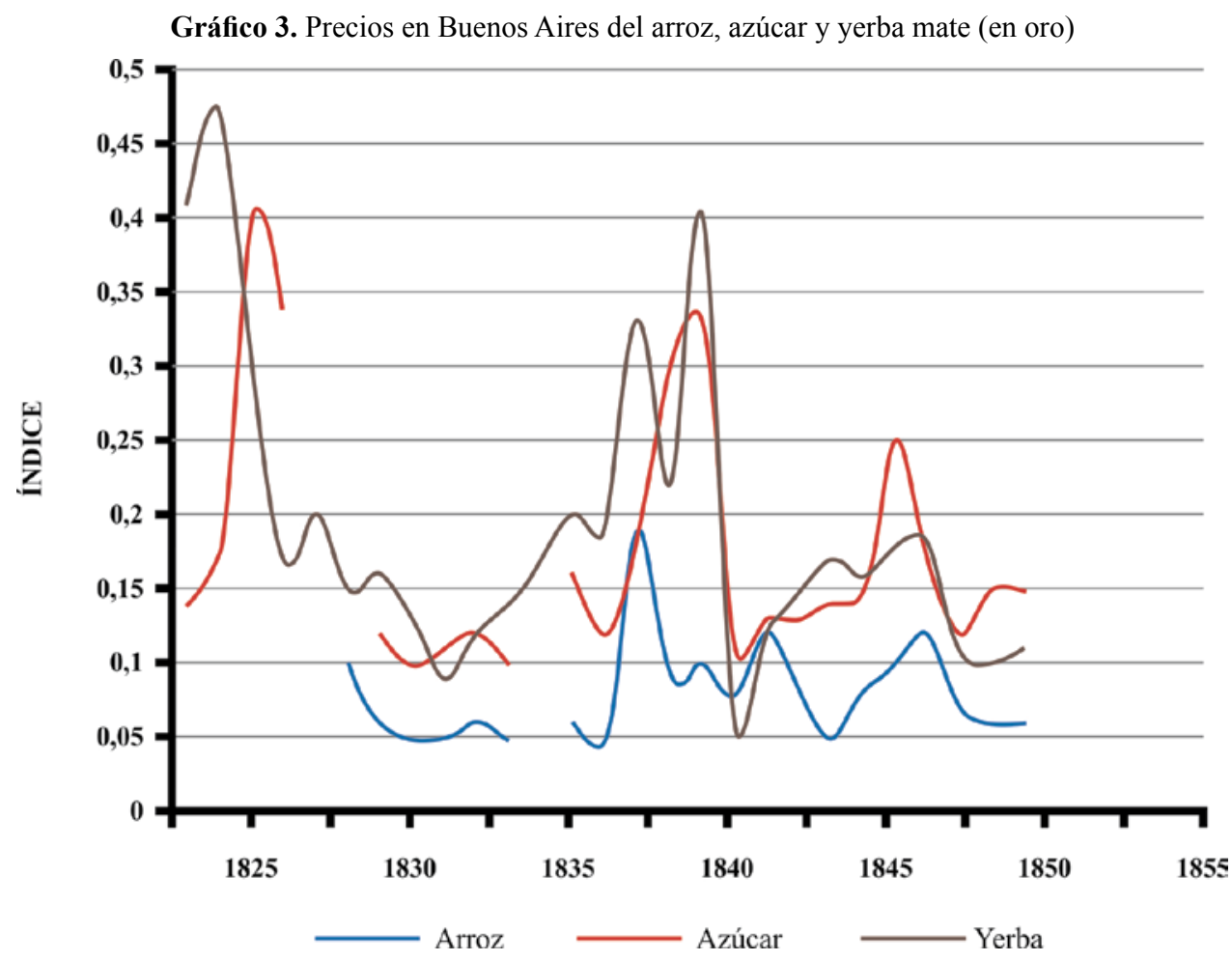


Schmit. Precios de bienes importados en Buenos Aires, 1824-1850.

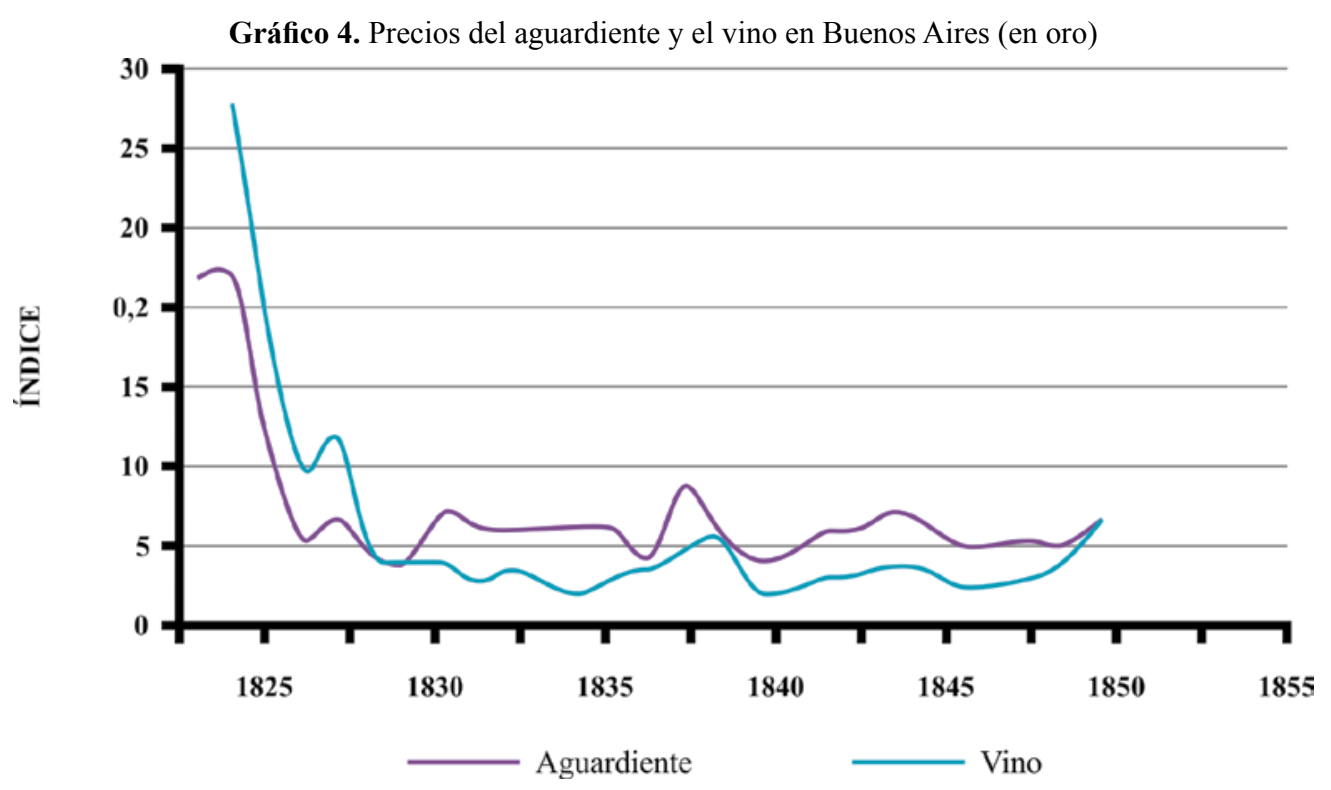

Por lo señalado entonces, no se puede concluir que todos los productos ultramarinos registraran un movimiento simultáneo, ya que al menos de este reducido número de bienes se puede concluir que -en valores constantes- los productos americanos tuvieron fuertes oscilaciones en los precios, en tanto que los restantes productos importados registraron una clara tendencia, casi permanente, a la baja.

Otra cuestión muy significativa para el análisis de aquellos precios en Buenos Aires es considerar la evolución de los precios de los bienes importados en pesos plata que era la moneda con la cual realizaban las operaciones las economías de las provincias del Interior que en gran medida se abastecían de los productos de ultramar en la plaza porteña.

En el gráfico 5 podemos observar que los precios de aquellos bienes en pesos plata, salvo el caso de algunos productos y durante pocos años, como la yerba, muestra una clara tendencia a la baja, lo cual no es una cuestión menor para estimar la evolución de las relaciones de articulación de las compras de los comerciantes del interior en la plaza porteña. Aquello implicaría que los precios en baja en pesos plata podría haber significado una mayor capacidad de consumo para aquellos que se abastecían, preferentemente, desde esta plaza y no desde otras opciones, como las existentes a través de los vínculos provenientes de los circuitos mercantiles del Pacífico, los cuales desde la década de 1830 también se articularon activamente desde las provincias de Cuyo y el centro y norte de la Confederación de la provincias rioplatenses. 
Gráfico 5. Precios de los bienes importados en Buenos Aires: arroz, azúcar, aceite, aguardiante, vino, sal y yerba mate (en pesos plata)

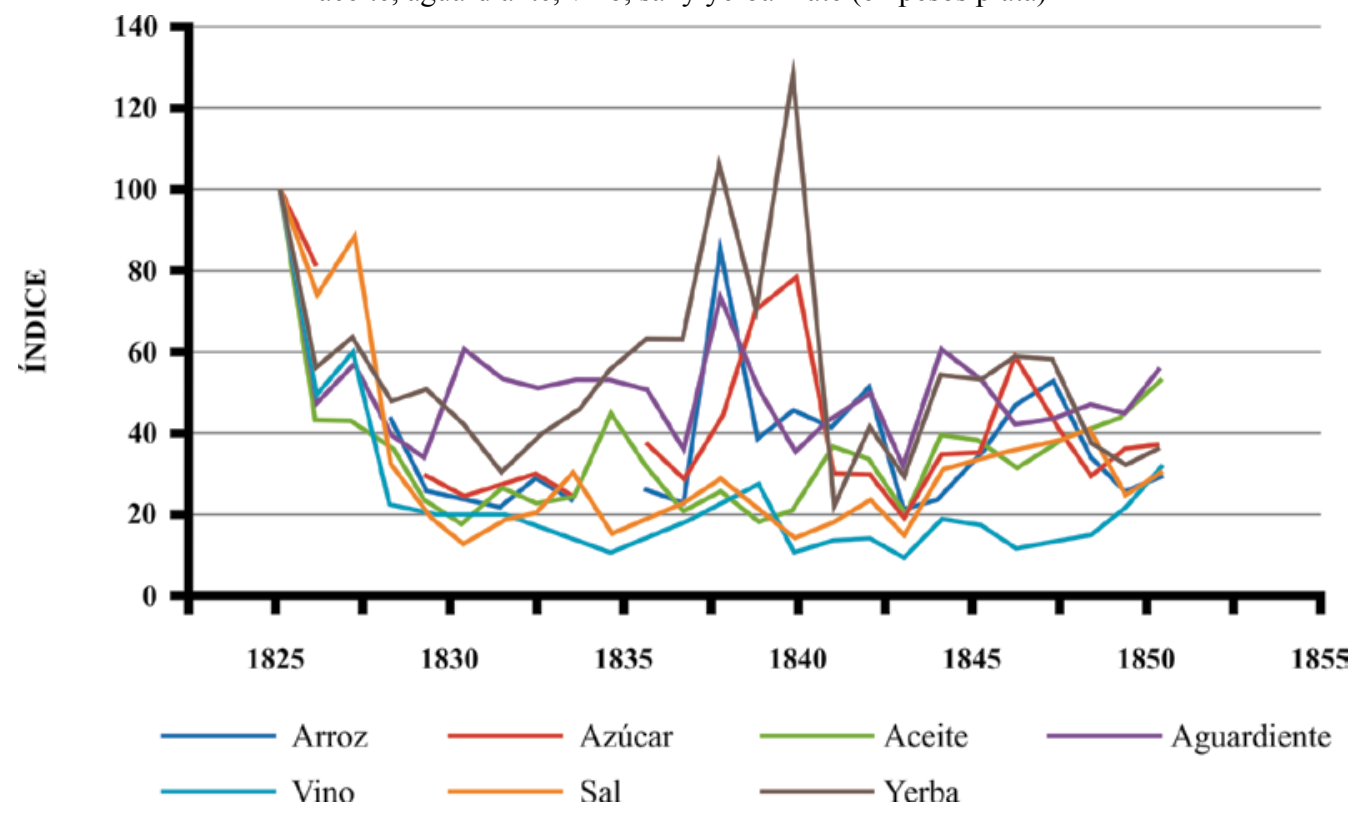

\section{Conclusiones}

Varios trabajos han mostrado que en Buenos Aires, durante el siglo XVIII, el índice de precios de los productos de ultramar tenía una tendencia a la baja en la primera parte de la centuria y más tarde, se mantuvieron estables (Cuesta, 2009). Pero en este estudio, sobre la primera mitad del siglo XIX, podemos confirmar que los bienes importados -al menos desde el decenio de 1820- tuvieron un cambio significativo en la evolución del nivel general de precios nominales (en pesos papel), con un incremento promedio de los mismos entre 1824 y 1850 de por lo menos seis veces. En una mirada global, el nivel de precios en pesos en papel del período analizado parece mostrar casi una constante de crecimiento, no obstante, el mismo fue más mesurado durante la primera década de 1824 a 1830, con una breve meseta hasta mitad del decenio de 1830 . Pero durante la década de 1840 -desde el segundo bloqueo al puerto de Buenos Airesel aumento de los precios fue muy fuerte y más volátil hasta fin del período analizado, en el cual parece comenzar a emerger nuevamente un cierto nivel de estabilidad y de potencial convergencia de precios.

Asimismo, es notable resaltar que dentro de aquella tendencia común hubo una clara diversidad de ritmos y momentos en la evolución de los precios de los diversos tipos de los bienes importados. Por todo ello, es necesario, para examinar más a fondo este tópico, continuar ampliando la canasta de bienes, sobre todo dentro de los llamados bienes importados de gran consumo, como los textiles, para continuar evaluando la variedad de comportamientos que es necesario conocer con mayor precisión. 
Aquellos cambios sin duda estuvieron muy marcados por los bloqueos comerciales al puerto de Buenos Aires, sobre todo para el caso de las importaciones. Pero en relación a los diversos momentos, el impacto de los bloqueos fue diferencial, con un peso mayor durante el segundo bloqueo a inicios de la década de 1840. Asimismo, la volatilidad de los bienes importados y de consumo masivo parece haber alcanzado mucha mayor inestabilidad durante la década de 1840 , todo lo cual debe haber afectado necesariamente la capacidad de consumo de los sectores, sobre todo los que dependían más de ingresos fijos y en papel moneda.

La otra cuestión fundamental para la economía rioplatense fue que los precios de bienes importados medidos en moneda metálica muestran con altibajos una tendencia de caída de precios a lo largo del período analizado. Pero dentro de aquella tendencia, la marcha de los mismos fue diversa respecto de sus precios relativos, de modo que la evolución en oro muestra un panorama no homogéneo dentro del cual algunos bienes, como la yerba y el azúcar, siguieron la tendencia más volátil con alzas y bajas y con una menor tendencia de descenso de su valor en oro en la plaza porteña. También en el mismo sentido, otro tópico aún más significativo fue que los precios de los bienes de ultramar en pesos plata, moneda en que operaron las actividades mercantiles de las provincias del interior, muestran a lo largo del período analizado una clara tendencia a la baja, lo cual es relevante para comprender y evaluar las potenciales balanzas comerciales y la evolución de las relaciones de articulación mercantil de las compras y ventas del interior de las provincias rioplatenses en la plaza de Buenos Aires. Aquello podría haber significado un potencial incremento del poder de compra en las relaciones mercantiles de intermediación en moneda fuerte en el mercado porteño.

\section{Referencias bibliográficas}

Sobre fuentes y metodología

Los precios del trabajo han sido tomados de las listas de precios mayoristas elaborados por la Junta de Comercio publicados en la prensa. Utilizamos los precios al por mayor de la Gaceta Mercantil y de la sección precios del British Packet (de la Biblioteca Nacional). Para los productos en base a los precios semanales se han elaborado precios promedios mensuales. Las unidades de los productos de importación son: aceite en arroba, aguardiente en pipa, vino en pipa, sal en fanega, yerba en arroba, azúcar en arroba, arroz en arroba.

Los valores de los precios unitarios y de los precios promedios están expresados en índices, todos con base en el año de 1824.

Los índices ponderados de precios han sido calculados en base a la fórmula de Laspeyres del siguiente modo:

\section{$\sum \mathrm{P} 1 \mathrm{Q} 0$}

$\sum \mathrm{P} 0 \mathrm{Q} 0$

$\mathrm{P} 1=$ precio anual, $\mathrm{P} 0=$ precio base, $\mathrm{Q} 0=$ cantidad base . 
Para definir la ponderación del peso de los bienes importados se ha tomado en cuenta el informe sobre las importaciones del Buenos Aires de los años de 1835 y 1837, con la ponderación siguiente de: bebidas $20 \%$, azúcar $30 \%$, yerba $30 \%$, sal 10\% y otros (aceite, arroz, fideos y galleta) 10\%. Informe sobre comercio de importación de Buenos Aires, Academia Nacional de la Historia, p. 31. Registro Oficial de la Provincia de Buenos Aires, 1835, 1836 y 1837. En este estudio, al no contar aún con una serie confiable, no se incorporan textiles en la canasta, ellos eran significativos en el consumo de bienes importados y su peso estimado rondaría entre el 20 al $25 \%$ del consumo en la plaza porteña.

Bibliografia:

Álvarez, J. 1929. Temas de Historia Económica Argentina, El Ateneo, Buenos Aires.

Amaral, S. 1989. "Alta inflación y precios relativos. El pago de las obligaciones en Buenos Aires, 1826-1834”, en: El Trimestre Económico, n. 221, México.

Amaral, S. 1988. "El descubrimiento de la financiación inflacionaria, Buenos Aires 1790-1830", en: Investigaciones y Ensayos, N. 37, Academia Nacional de la Historia, Buenos Aires.

Banzato, G. (Dir.) 2013. Tierras rurales. Politicas, transacciones y mercados en Argentina, 1780-1914, Prohistoria, Rosario.

Barba, F. 1999. Aproximación al estudio de los precios y salarios en Buenos Aires desde fines del siglo XVIII hasta 1860, Universidad Nacional de La Plata, La Plata.

Bilbao, M. E. 1985. "Evolución de precios de la yerba mate y azúcar en Buenos Aires, 1823-1832", en: VII Jornadas de la AAHE, Rosario.

Broide, J. 1951. La evolución de los precios pecuarios argentinos en el periodo 18301850, Instituto de Economía, FCE, Buenos Aires.

Burgin, M. 1960. Aspectos económicos del federalismo argentino, Ed. Hachette, Buenos Aires.

Cuesta, M. 2009. Precios, población y producción. La economía de Buenos Aires en el siglo XVIII. Ed. Temas Grupo, Buenos Aires.

Djenderedjian, J. 2013. "La economía: estructura productiva, comercio y transportes". En: Ternavasio (Dir.), Historia de la Provincia de Buenos Aires, T. 3. UNIPEEDHASA, Buenos Aires.

Garavaglia, J. C. 1995. "Precios de los productos rurales y precios de la tierra en la campaña de Buenos Aires, 1750-1826”, en: Boletín del Instituto Ravignani, N. 11, Buenos Aires.

Garavaglia, J. C. 2004. "La economía rural de la campaña de Buenos Aires vista a través de sus precios: 1756-1852", en: Fradkin y Garavaglia (Ed.), En busca de un tiempo perdido. La economía de Buenos Aires en el país de la abundancia, 1750-1865, Ed. Prometeo, Buenos Aires.

Gelman J. y Santilli, D. 2014. "Mar de fondo. Salarios, precios y cambios en las condiciones de vida de los pobladores de Buenos Aires en una época convulsa, 1810-1870". En: Santilli, Gelman y Fradkin (Comps.), Rebeldes con causa. Prometeo, Buenos Aires. 
Gorostegui de Torres, H. 1962-63. "Los precios del trigo en Buenos Aires durante el gobierno de Rosas", en: Anuario de Investigaciones Históricas, N. 6, UNL, Rosario.

Halperin Donghi T. 1978. "Bloqueos, emisiones monetarias y precios en el Buenos Aires rosista, 1838-1850", en: Historia, problema y promesa. Homenaje a J. Basadre, UPL, Lima.

Halperin Donghi T. 1982. Guerra y Finanzas en los orígenes del Estado Argentino, 1791-1850, Ed. U. Belgrano, Buenos Aires.

Halperin Donghi T. 1963. "La expansión ganadera en la campaña de Buenos Aires, 1810-1852”, en: Desarrollo Económico, vol. 1, N. 2, Buenos Aires.

Irigoin, M. A. 2004. "La expansión ganadera en la campaña de Buenos Aires, 18201860: ¿una consecuencia de la financiación inflacionaria del déficit fiscal?, en: Fradkin y Garavaglia (Ed.), En busca de un tiempo perdido. La economía de Buenos Aires en el país de la abundancia, 1750-1865, Ed. Prometeo, Buenos Aires.

Irigoin, M. A. 2000. "La expansión ganadera en la campaña de Buenos Aires, 1820-1860. Las consecuencias de la inflación y el uso del papel moneda en la financiación del déficit fiscal". En: XVII Jornadas de la AAHE, Tucumán.

Irigoin, M. A. 2001. "Papel moneda inconvertible, inflación y la expansión de la ganadería en Buenos Aires, 1820-1860”, Programa de Historia del siglo XIX, Instituto Ravignani, Buenos Aires.

Irigoin M. A. y Salazar, E. 1996. Linking political events and economic uncertainty: an econometric examination of the volatility in the Buenos Aires paper peso rate of exchange, 1826-1866. Department of Economic History, London Scholl of Economics, London.

Irigoin M. y Schmit R. 2002. La desintegración de la Economía Colonial, Ed. Biblos, Buenos Aires.

Mateo, J. 2013. "La sociedad: población, estructura social y migraciones", en: Ternavasio (Dir.), Historia de la Provincia de Buenos Aires, T. 3. UNIPE-EDHASA, Buenos Aires.

Newland, C. 1998. "Exports and terms of trade in Argentine, 1811-1870", en: Bulletin Latin American, Vol. 17, N. 3, Gran Bretania, 409-416.

Rosal, M. y Schmit, R. 1999. "Del reformismo colonial borbónico al librecomercio: las exportaciones pecuarias del Río de la Plata, 1768-1854”, en: Boletín del Instituto Ravignani, n. 20. Buenos Aires.

Rosal, M. y Schmit R. 2004. "Las exportaciones pecuarias bonaerenses y el espacio mercantil rioplatense, 1768-1854", en: Fradkin y Garavaglia (Ed.), En busca de un tiempo perdido. La economía de Buenos Aires en el país de la abundancia, 1750-1865, Ed. Prometeo, Buenos Aires.

Schmit R. 2013. "Finanzas públicas, puerto y recursos financieros", en: Ternavasio (Dir), Historia de la Provincia de Buenos Aires, T. 3, UNIPE-EDHASA, Buenos Aires. 
Schmit R. 1991. "Mercados y flujos comerciales en los Estados provinciales argentino de la primera mitad del siglo XIX", en: Boletín del Instituto Ravignani, N. 4, FFyL-FCE, Buenos Aires.

Tabla 2. Índice de precios de bienes importados en Buenos Aires, 1824-1850

\begin{tabular}{|c|c|c|c|c|c|c|c|}
\hline & Arroz & Azúcar & Aceite & Aguardiente & Vino & Sal & Yerba \\
\hline 1824 & 100 & 100 & 100 & 100 & 100 & 100 & 100 \\
\hline 1825 & & 134 & 93,8 & 100 & 100 & 100 & 114,3 \\
\hline 1826 & & 506 & 98,9 & 92,2 & 102,7 & 125 & 128,5 \\
\hline 1827 & 1101 & 812 & 86,6 & 87,5 & 101,6 & 183,3 & 143 \\
\hline 1828 & & & 74,2 & 90,6 & 107,1 & 191,7 & 143 \\
\hline 1829 & 678 & & 103,1 & 102,8 & 64,8 & 116,7 & 171,4 \\
\hline 1830 & 602 & 633 & 99 & 129,3 & 87,8 & 111,7 & 271,4 \\
\hline 1831 & 513 & 505 & 70,1 & 218,1 & 83,7 & 66,7 & 214,2 \\
\hline 1832 & 500 & 537 & 103,1 & 193,1 & 86,2 & 91,7 & 157,1 \\
\hline 1833 & 695 & 652 & 97 & 200 & 78,4 & 112,5 & 214,3 \\
\hline 1834 & 569 & 526 & 103,1 & 203,1 & 60,9 & 158,4 & 242,8 \\
\hline 1835 & & & 185 & 203,1 & 48,5 & 84,2 & 300 \\
\hline 1836 & 633 & 816 & 137 & 199 & 67,1 & 108,4 & 342,8 \\
\hline 1837 & 607 & 690 & 99 & 156,2 & 87,9 & 133,4 & 371,4 \\
\hline 1838 & 2457 & 1145 & 132 & 350 & 125,5 & 191,7 & 700 \\
\hline 1839 & 1949 & 3203 & 165 & 422,5 & 257,3 & 250 & 800 \\
\hline 1840 & 3373 & 5198 & 289 & 437,5 & 160,7 & 250 & 2142,8 \\
\hline 1841 & 2542 & 1673 & 396 & 440,6 & 156,3 & 258,3 & 314,3 \\
\hline 1842 & 2822 & 1514 & 330 & 445,3 & 151,7 & 291,7 & 514,3 \\
\hline 1843 & 1847 & 1539 & 301 & 445,3 & 160 & 291,7 & 600 \\
\hline 1844 & 1093 & 1401 & 313 & 435,9 & 157 & 308,3 & 551,4 \\
\hline 1845 & 1733 & 1598 & 338 & 437,5 & 163 & 375 & 600 \\
\hline 1846 & 3347 & 3849 & 400 & 500 & 171 & 583,3 & 971,4 \\
\hline 1847 & 3665 & 2635 & 454 & 495,3 & 180 & 583,3 & 921,4 \\
\hline 1848 & 2295 & 1849 & 495 & 527,1 & 205 & 625 & 594,2 \\
\hline 1849 & 1616 & 1946 & 462 & 535,9 & 238 & 333,3 & 442,8 \\
\hline 1850 & 1423 & 1615 & 445 & 443,7 & 284 & 333,3 & 411,4 \\
\hline
\end{tabular}

